Article

\title{
Synthesis and DFT Investigation of New Low-Melting Supramolecular Schiff Base Ionic Liquid Crystals
}

\author{
Sayed Z. Mohammady ${ }^{1, *(D)}$, Daifallah M. Aldhayan ${ }^{1}$, Mohsen M. T. El-Tahawy ${ }^{2,3}$, Mohammed T. Alazmid ${ }^{4}$, \\ Yeldez El Kilany ${ }^{4}$, Mohamed A. Zakaria ${ }^{4}$ (D), Khulood A. Abu Al-Ola ${ }^{5}$ and Mohamed Hagar ${ }^{4, *(D)}$
}

1 Chemistry Department, Faculty of Science, King Saud University, Riyadh 10251, Saudi Arabia; aldhayan@ksu.edu.sa

2 Departimento di Chimica Industriale "Toso Montanare", Unniversita di Bologna, Viale del Risorgimento, 4, 40136 Bologna, Italy; mohsenmamdouh.tahawy@unibo.it

3 Chemistry Department, Faculty of Science, Damanhour University, Damanhour 22511, Egypt

4 Chemistry Department, Faculty of Science, Alexandria University, Alexandria 21321, Egypt;

Mnalazmi90@gmail.com (M.T.A.); yeldez244@yahoo.com (Y.E.K.); mohamed.zakaria@alexu.edu.eg (M.A.Z.)

5 Chemistry Department, College of Sciences, Taibah University, Medina 39345, Saudi Arabia; Kabualola@taibahu.edu.sa

* Correspondence: sahmed2.c@ksu.edu.sa (S.Z.M.); mohamedhaggar@gmail.com (M.H.)

check for

updates

Citation: Mohammady, S.Z.;

Aldhayan, D.M.; El-Tahawy, M.M.T.; Alazmid, M.T.; El Kilany, Y.; Zakaria, M.A.; Abu Al-Ola, K.A.; Hagar, M. Synthesis and DFT Investigation of New Low-Melting Supramolecular Schiff Base Ionic Liquid Crystals. Crystals 2022, 12, 136. https:// doi.org/10.3390/cryst12020136

Academic Editor: Shujun Zhang

Received: 12 December 2021

Accepted: 17 January 2022

Published: 19 January 2022

Publisher's Note: MDPI stays neutral with regard to jurisdictional claims in published maps and institutional affiliations.

Copyright: (c) 2022 by the authors. Licensee MDPI, Basel, Switzerland. This article is an open access article distributed under the terms and conditions of the Creative Commons Attribution (CC BY) license (https:// creativecommons.org/licenses/by/ $4.0 /)$.

\begin{abstract}
Supramolecular, low-melting (near or below $0.0^{\circ} \mathrm{C}$ ) ionic liquid crystals with two rings of Schiff bases were prepared and studied. The Schiff bases were synthesized using 4-substituted aniline derivatives and 4-pyridine carbaldehyde and then mixed in equimolar amounts with linear 1-bromoalkanes of different chain lengths, namely C6, C8, and C14. The mesomorphic behavior and thermal properties of the compounds were determined by polarized optical microscopy (POM) and differential scanning calorimetry (DSC). Only the ionic liquids analogous with 1-bromotetradecane exhibit mesomorphic behavior. All, except the smectic A (SmA) monomorphic fluorine-substituted complex, show dimorphic enantiotropic mesophases, namely SmA followed by nematic $(\mathrm{N})$ mesophases depending on the temperature rise. The DSC and POM results for the induced mesophases were then treated with density functional theory calculations (DFT). The results showed that both the polarity of the polar groups and the length of the alkyl groups strongly influence the mesomorphic properties of the ionic liquids.
\end{abstract}

Keywords: supramolecular; low-melting ionic liquids; mesomorphic behavior; DFT

\section{Introduction}

Ionic liquids (ILs) can be defined as ionic materials possessing low melting points of less than $100^{\circ} \mathrm{C}$. Moreover, low-mass calamitic liquid crystals, consisting of two aromatic rings with at least one terminal substituent, are capable of showing the nematic phase of important applications at room temperature [1-3]. In general, ILs consist of organic or inorganic anions usually coupled with asymmetric large organic cations. ILs possess a large number of different physicochemical properties that qualify these materials for specific applications and often lead to significant results when applied compared to their behavior in conventional solvents [4,5]. Moreover, ILs are considered to be environmentally friendly solvents, since they usually show very low vapor pressure [6]. In addition, ILs reveal stability towards thermal degradation [7-9]. Therefore, they can be used as ideal substitutes for conventional organic solvents. Moreover, they exhibit exceptional solubility properties for inorganic, organic and organometallic compounds. ILs play an important role as starting materials for $\mathrm{N}$-heterocyclic carbenes, which can be used in a variety of catalytic reactions [10-13]. At the macroscopic level, however, ILCs are identical to LCs in every way, because the material's behavior is determined by the phase structure. As a result, ILCs are gaining popularity since they are projected to combine the numerous intriguing technical applications of ILs and LCs [14,15]. 
In the last three decades, ILs were massively investigated as they display broad electrochemical windows, elevated ionic conductivity [16] and a wide temperature range of their liquid state. Furthermore, many of the physical characteristics of ILs such as melting point, density, viscosity, polarity, and enthalpy of vaporization can be tailored simply through variation of their anion and cation pairing [17]. A lot of effort has been attempted to fabricate new classes of ILs, known as functionalized ionic liquids (FILs), which bear different functional groups in their cationic portion [18-23]. Functionalization of the cationic moiety of the FILs allow them to be tunable for specific applications such as reduced catalyst leaching and increased catalytic stability [24,25].

It is worth noting that Schiff base compounds are considered as a distinguished class of ligands that play a vital role in coordination chemistry. They display diverse chelating capability [26-28], functionalities [29] and various ranges of pharmacological, biological, and antitumor activities. Schiff bases involving hetero-atoms such as $\mathrm{N}$ and $\mathrm{S}$ in their chemical structures exhibit special importance due to their strong ability to coordinate with a variety of transition metal ions, affording a lot of uncommon configurations [30-32].

In this contribution, we extended our recent work of supramolecular Schiff baseinduced liquid crystalline materials $[33,34]$ to synthesize functionalized ionic liquid crystal (FILCs) two-ring Schiff bases with melting points close to or lower than $0.0{ }^{\circ} \mathrm{C}$. These Schiff bases were designed using 4-substituted aniline derivatives and 4-pyridine carbaldehyde and finally paired with linear 1-bromoalkanes of various chain lengths. We investigated the mesomorphic behavior and thermal properties of these FILCs using polarized optical microscopy (POM) and differential thermal analysis (DSC). In addition, the DSC and POM results of the studied materials were linked using density functional theory (DFT).

\section{Materials and Methods}

Chemicals were obtained from TCI Company, Japan (Tokyo Chemical Industry, Tokyo, Japan). Their purity is more than $98 \%$ in all compounds. Schiff bases were prepared and recrystallized twice from ethanol/water mixture and were checked to be TLC pure (Scheme 1).

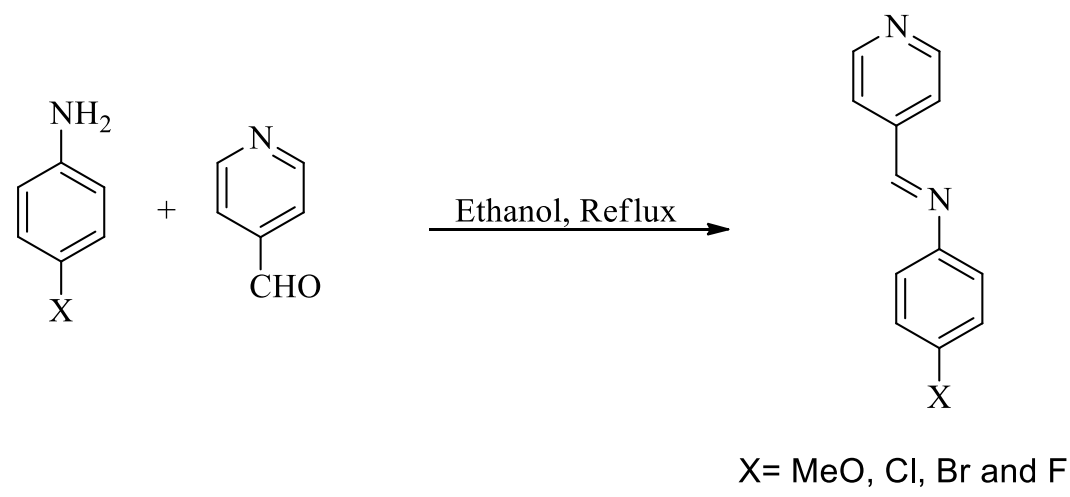

Scheme 1. Schiff bases I-IV preparation.

\section{Schiff Bases Synthesis}

The Schiff bases were identified according to their reported melting points: $\mathbf{I}\left(98^{\circ} \mathrm{C}\right)$ [35], II $\left(74^{\circ} \mathrm{C}\right)$ [36], III $\left(80^{\circ} \mathrm{C}\right)$ [35], and IV $\left(82^{\circ} \mathrm{C}\right)$.

\section{The Ionic Liquids Synthesis}

The Schiff base ionic liquids were prepared by mixing 1:1 molar ratios of any two complementary components of the particular Schiff bases with linear 1-bromo alkanes at various chain lengths, namely $\mathrm{C} 6, \mathrm{C} 8$, and $\mathrm{C} 14$; melting the appropriate amounts with stirring to produce a thorough blend; and then, cooling with stirring to room temperature to obtain the ionic liquids (Scheme 2). 


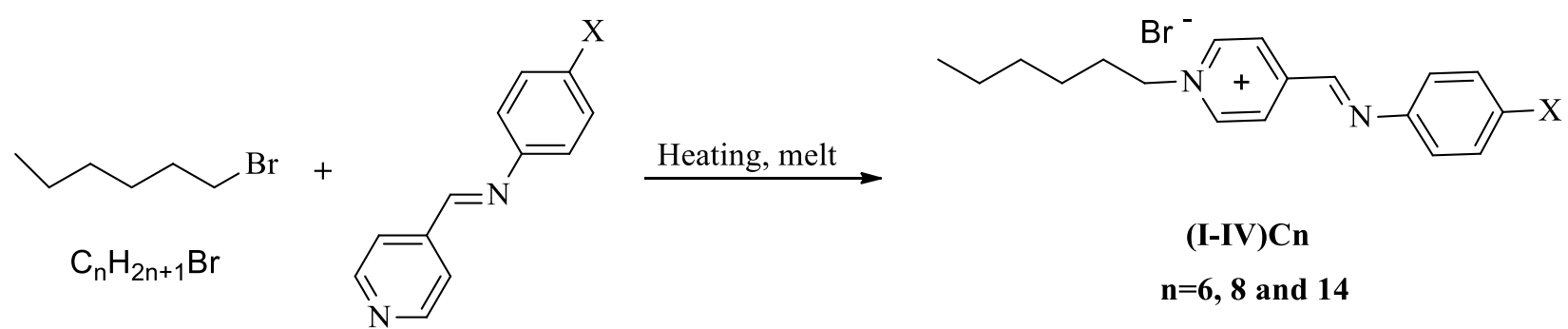

(I-IV) Schiff base

Scheme 2. Preparation of the ionic liquid crystals ((I-IV)Cn).

The phase changes characterizing the materials were verified via differential scanning calorimetry (DSC), with a Shimadzu DSC-60A (SHIMADZU, Tokyo, Japan). A quantity of 2-3 mg was encapsulated in Al pans and heated or cooled in a dry nitrogen atmosphere. The samples were heated using a heating speed of $10.0^{\circ} \mathrm{C} / \mathrm{min}$ during the tests. The samples were heated to $100{ }^{\circ} \mathrm{C}$ from room temperature and then cooled to $-20{ }^{\circ} \mathrm{C}$ at the same time rate. Finally, samples were reheated again to $150^{\circ} \mathrm{C}$, all under $\mathrm{N}_{2}$ gas atmosphere. The accuracy in temperature monitoring is $<1.0^{\circ} \mathrm{C}$.

\section{Results and Discussion}

The two-ring ILs 1:1 compounds ((I-IV)Cn) were investigated in terms of mesophases and optical analyses. Table 1 epitomizes the transition temperatures, $\mathrm{T}$, and their associated enthalpies, H, of all observed transitions, as determined by DSC measurements, for all prepared ((I-IV)Cn) ILs.

Table 1. Phase transitions: temperatures $\left(\mathrm{T},{ }^{\circ} \mathrm{C}\right)$ and enthalpies $(\Delta \mathrm{H}, \mathrm{kJ} / \mathrm{mol})$ for the $((\mathrm{I}-\mathrm{IV}) \mathrm{Cn})$ functionalized ionic liquids. The abbreviations $\mathrm{Cr}-\mathrm{I}, \mathrm{Cr}-\mathrm{SmA}, \mathrm{SmA}-\mathrm{N}$ and N-I denote the crystalline to isotropic, crystalline to smectic $\mathrm{A}$, smectic $\mathrm{A}$ to nematic and nematic to isotropic transitions, respectively.

\begin{tabular}{|c|c|c|c|c|c|c|c|c|c|}
\hline \multicolumn{2}{|c|}{ Compounds } & $\begin{array}{c}{ }^{\circ} \mathrm{C} \\
\mathrm{T}_{\mathrm{Cr}-\mathrm{I}}\end{array}$ & $\begin{array}{l}\mathrm{kJ} / \mathrm{mol} \\
\Delta \mathrm{H}_{\mathrm{Cr}-\mathrm{I}}\end{array}$ & $\begin{array}{c}{ }^{\circ} \mathrm{C} \\
\mathrm{T}_{\mathrm{Cr}-\mathrm{SmA}}\end{array}$ & $\begin{array}{c}\mathbf{k J} / \mathrm{mol} \\
\Delta \mathrm{H}_{\mathrm{Cr}-\mathrm{SmA}}\end{array}$ & $\begin{array}{c}{ }^{\circ} \mathrm{C} \\
\mathrm{T}_{\mathrm{SmA-N}}\end{array}$ & $\begin{array}{c}\mathrm{kJ} / \mathrm{mol} \\
\Delta \mathrm{H}_{\mathrm{SmA}-\mathrm{N}}\end{array}$ & $\begin{array}{c}{ }^{\circ} \mathrm{C} \\
\mathrm{T}_{\mathrm{N}-\mathrm{I}}\end{array}$ & $\begin{array}{l}\mathrm{kJ} / \mathrm{mol} \\
\Delta \mathrm{H}_{\mathrm{N}-\mathrm{I}}\end{array}$ \\
\hline I/C6 & $\mathrm{MeO}$ & 90.1 & 16.9 & & & & & & \\
\hline II/C6 & $\mathrm{Cl}$ & 84.4 & 14.4 & & & & & & \\
\hline III/C6 & $\mathrm{Br}$ & 107.3 & 15.4 & & & & & & \\
\hline IV/C6 & $\mathbf{F}$ & 88.7 & 17.2 & & & & & & \\
\hline I/C8 & $\mathrm{MeO}$ & 97.0 & 16.0 & & & & & & \\
\hline II/C8 & $\mathrm{Cl}$ & 80.0 & 12.7 & & & & & & \\
\hline III/C8 & $\mathrm{Br}$ & 107.5 & 14.5 & & & & & & \\
\hline IV/C8 & $\mathbf{F}$ & 136.6 & 20.8 & & & & & & \\
\hline I/C14 & $\mathrm{MeO}$ & & & 3.4 & 8.7 & 65.9 & 0.70 & 84.6 & 2.36 \\
\hline II/C14 & $\mathrm{Cl}$ & & & 1.6 & 12.0 & 26.2 & 0.28 & 59.4 & 2.68 \\
\hline III/C14 & $\mathrm{Br}$ & & & -0.8 & 6.3 & 21.4 & 0.11 & 96.1 & 7.20 \\
\hline IV/C14 & $\mathbf{F}$ & & & 3.5 & 9.0 & & & 78.2 & 8.60 \\
\hline
\end{tabular}

Figure 1 displays the DSC thermogram of sample I/C14 at a heating rate of $10.0^{\circ} \mathrm{C} / \mathrm{min}$. We will only consider the results obtained from the second heating run in this manuscript. The temperature dependence of the heat capacity of the compound manifests an endothermic peak at $3.4^{\circ} \mathrm{C}$ corresponding to a crystalline to smectic A (Cr-SmA) mesomorphic phase transition. By increasing the temperatures, a second endothermic peak at $65.9{ }^{\circ} \mathrm{C}$, referring to $\mathrm{SmA}$ to nematic transition $(\mathrm{SmA}-\mathrm{N})$, is monitored. Finally, nematic to isotropic $(\mathrm{N}-\mathrm{I})$ transition is detected at $84.6^{\circ} \mathrm{C}$. The total mesomorphic temperature range of the material is satisfying $\left(81.2^{\circ} \mathrm{C}\right)$. Both mesomorphic transitions are observed upon cooling, proving the enantiotropic behavior of the observed mesophases. Displaying the mesophase 
behavior upon cooling can be taken as direct evidence for the thermal stabilities of the ILCs in the entire investigated temperature range. The mesophase textures have been identified by the polarized optical microscope, as shown in Figure 2, Table 1.

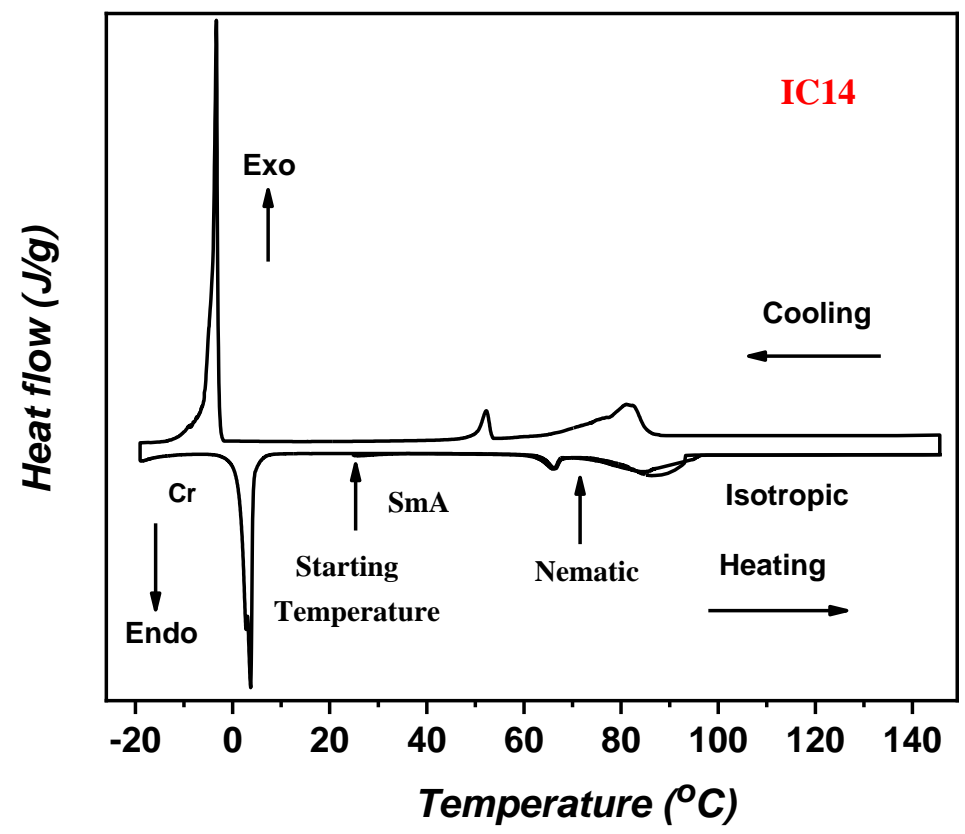

Figure 1. DSC heating/cooling cycles of I/C14 ionic liquid crystal (ILC) sample bearing MeO polar group and alkyl chain length of $\mathrm{C} 14$.

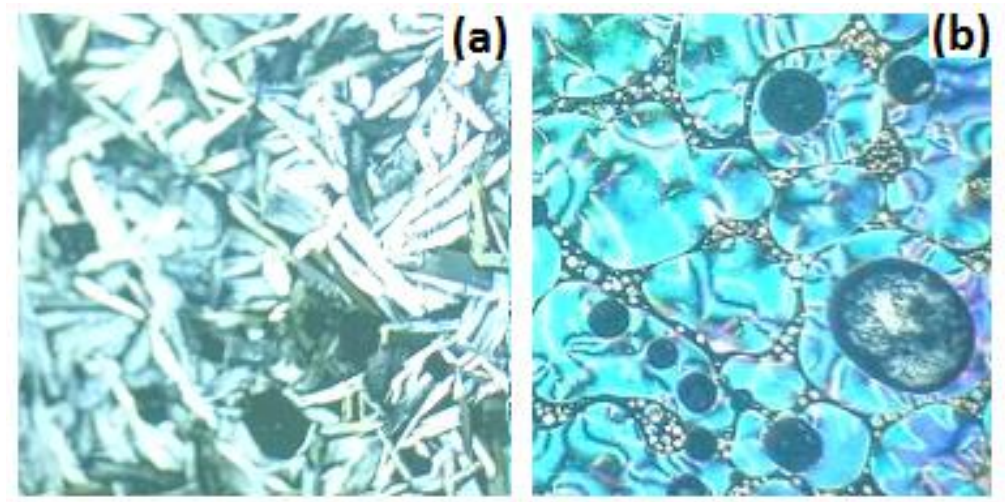

Figure 2. Mesophase textures observed by POM during heating cycle of compound II/C14 smectic A phase at $24.0^{\circ} \mathrm{C}(\mathbf{a})$ and compound $\mathrm{I} / \mathrm{C} 14$ nematic phase at $75.0^{\circ} \mathrm{C}(\mathbf{b})$.

The DSC investigations (Table 1) show that the ILC analogues incorporating the 1-bromotetradecane exhibit mesomorphic behavior. The rest of the IL complexes formed with the 1-bromohexane and 1-bromooctane are non-mesomorphic, irrespective of the Schiff base moiety contributing in the ILs. In addition, all the ILs involving 1-bromotetradecane reveal dimorphic enantiotropic mesophases. According to the temperature elevation, two transitions are observed, namely Cr-SmA followed by SmA-N mesophase transitions. The only exception is shown for the fluoro-substituted ILCs (IV/C14), which reveals a monomorphic SmA monotropic behavior.

The impact of variation of the polar group on the mesomorphic behavior of the (I-IV)/C14 ILCs is shown in Table 1. The influence of the polar substituent on the temperature ranges of the different mesophases ( $\mathrm{SmA}$ and $\mathrm{N}$ ), as well as the total mesomorphic temperature range, is pronounced. The ILC (I/C14) bearing the electron-releasing $\mathrm{MeO}$ group shows $\mathrm{SmA}$ and $\mathrm{N}$ mesophase ranges of 62.5 and $17.8^{\circ} \mathrm{C}$, respectively (a total 
mesomorphic range of $81.2^{\circ} \mathrm{C}$ ). In addition, the halide derivatives exhibited overall mesomorphic ranges of $57.8,96.6$ and $74.7^{\circ} \mathrm{C}$ for $\mathrm{Cl}, \mathrm{Br}$, and $\mathrm{F}$, respectively, which indicated a wide range of temperature for the mesomorphic behavior in all the samples. It can be noticed that the smectogenic mesomorphic range is enhanced in the order $\mathrm{MeO}>\mathrm{Cl}>\mathrm{Br}$ (Table 1), while the nematogenic behavior is generally enhanced in the order $\mathrm{Br}>\mathrm{Cl}>\mathrm{Me}$, i.e., upon the increase in negative inductive effect. The fluoro-derivative is the only exception, as mentioned above. The highly electron-withdrawing $\mathrm{F}$ group reveals only a SmA mesophase with a mesorange of $74.7^{\circ} \mathrm{C}$. This wide SmA mesophase range could be explained by the mesomeric resonance effect of the extremely small compact fluoro group. This effect could raise the $\pi$-cloud loop and promote the degree of $\pi-\pi$ stacking in the fluoro-substituted ILC to the other derivatives. In other words, the incorporation of the small compact fluorine atom with the highest negative inductive effect only enhances the formation of the SmA mesophase $\left(74.7^{\circ} \mathrm{C}\right)$, rather than the $\mathrm{N}$ phase. The highly parallel interaction that could be promoted by the $\mathrm{F}$ atom could be responsible for the enhanced SmA mesophase.

\section{DFT Theoretical Calculations}

\section{Geometrical Structures}

All the investigated compounds, (I-IV)C8, were optimized employing the DFT method using Gaussian 09 software (University of Cincinnati Libraries, OH, USA). The calculations were performed in gas phase using the B3LYP, 6-311g $(\mathrm{d}, \mathrm{p})$. Subsequence frequency counting was carried out to establish the most optimized real structures with the absence of imaginary frequency (Figure 3).

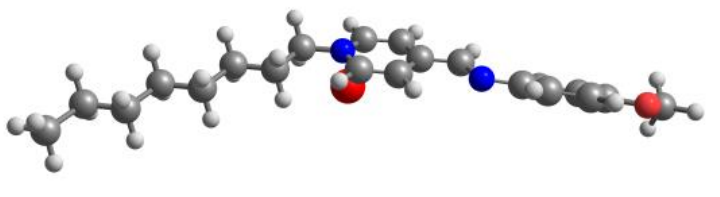

1/C8

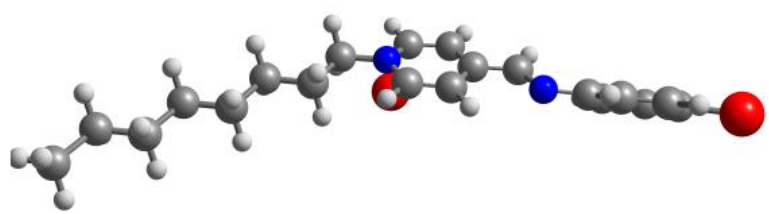

III/C8

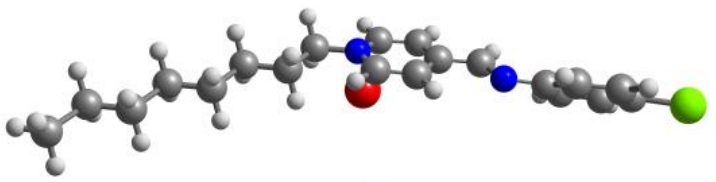

II/C8

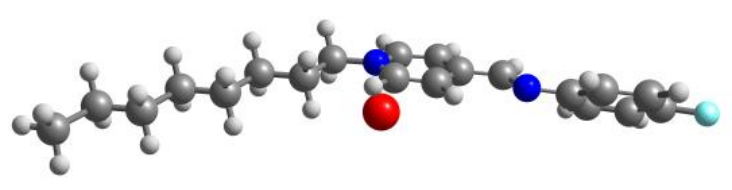

IV/C8

Figure 3. Calculated molecular geometrical the investigated compounds (I-IV)C8.

The relationships among the evaluated dimension parameters of all the prepared ILs, which are used to explain the mesomorphic properties including texture type, mesomorphic range, and stability, are shown in Table 2 . The variation in aspect ratio of the compounds (length-to-width ratio) with the mesomorphic temperature range of the $\operatorname{SmA}$ and $\mathrm{N}$ mesophases of the compounds is displayed in Figure $4 \mathrm{a}, \mathrm{b}$. 
Table 2. Mesomorphic parameters, polarizability, $\alpha$, and aspect ratio of the investigated compounds.

\begin{tabular}{|c|c|c|c|c|c|c|c|}
\hline \multirow{2}{*}{ Compounds } & \multirow{2}{*}{$\Delta \mathrm{T}_{\mathrm{C}}$} & \multirow{2}{*}{$\Delta \mathrm{T}_{\mathrm{SmA}}$} & \multirow{2}{*}{$\Delta T_{N}$} & \multirow{2}{*}{$\begin{array}{c}\text { Dipole } \\
\text { Moment, } \mu\end{array}$} & \multicolumn{2}{|c|}{ Dimension Á } & \multirow{2}{*}{$\begin{array}{c}\text { Aspect Ratio } \\
\text { (L/D) }\end{array}$} \\
\hline & & & & & Width (D) & Length (L) & \\
\hline I/C6 & 0 & 0 & 0 & 6.20 & 9.51 & 23.00 & 2.42 \\
\hline $\mathrm{I} / \mathrm{C} 8$ & 0 & 0 & 0 & 6.21 & 9.67 & 25.40 & 2.63 \\
\hline I/C14 & 81.2 & 62.5 & 18.7 & 6.22 & 9.85 & 34.54 & 3.55 \\
\hline II/C14 & 57.8 & 24.6 & 33.2 & 8.18 & 8.96 & 32.43 & 3.60 \\
\hline III/C14 & 96.9 & 22.2 & 74.7 & 7.98 & 9.05 & 32.74 & 3.62 \\
\hline IV/C14 & 74.7 & 74.7 & 0 & 8.16 & 9.00 & 31.54 & 3.52 \\
\hline
\end{tabular}
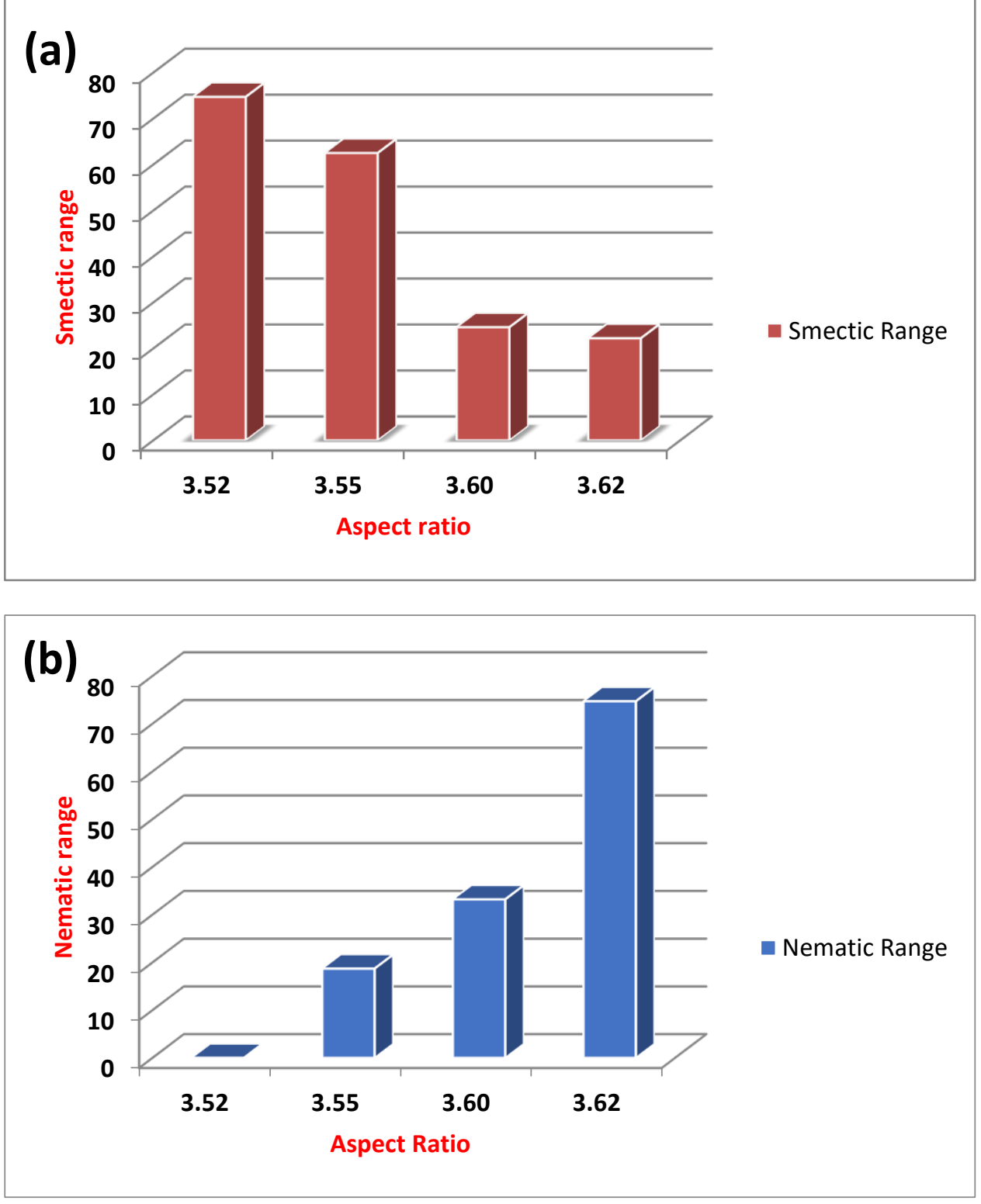

Figure 4. The relation between the aspect ratio and nematic (a) and smectic (b) total ranges of the investigated compounds (I-IV)C14.

It is well known that the intermolecular interaction increases upon the elevation of aspect ratio [37-40]. At high aspect ratios, the area of the intermolecular interaction increases. Additionally, the degree of molecular packing increases and the possibility of 
introducing a more ordered smectic mesophase dominates over the less ordered nematic mesophase. However, in our present series the situation is reversed: the nematic range increases as the aspect ratio increases and the smectic mesorange decreases. This finding can be illustrated in terms of the change in the dipole moment. Such little change in the dipole moment could affect the competitive lateral and terminal intermolecular interaction of the compounds (Table 2).

Figure 5 illustrates the relation between the type of the compact polar group of the prepared ILCs and the mesomorphic range (either smectic or nematic). A direct relationship can be noted between the type of terminal compact polar group and the mesomorphic range. For the high electronegative compact F-atom, the smectic mesophase is the dominant mesophase over the nematic one due to its high degree of intermolecular interaction that may enhance the existence of smectic over the nematic mesophase. However, the methoxy group of high mesomeric resonance effect with large space filling showed higher overall mesomorphic smectic range than the nematic mesophase. As indicated, due to the greater degree of alkyl aggregation of the methoxy chain, the smectic range increases $[33,34,41]$.
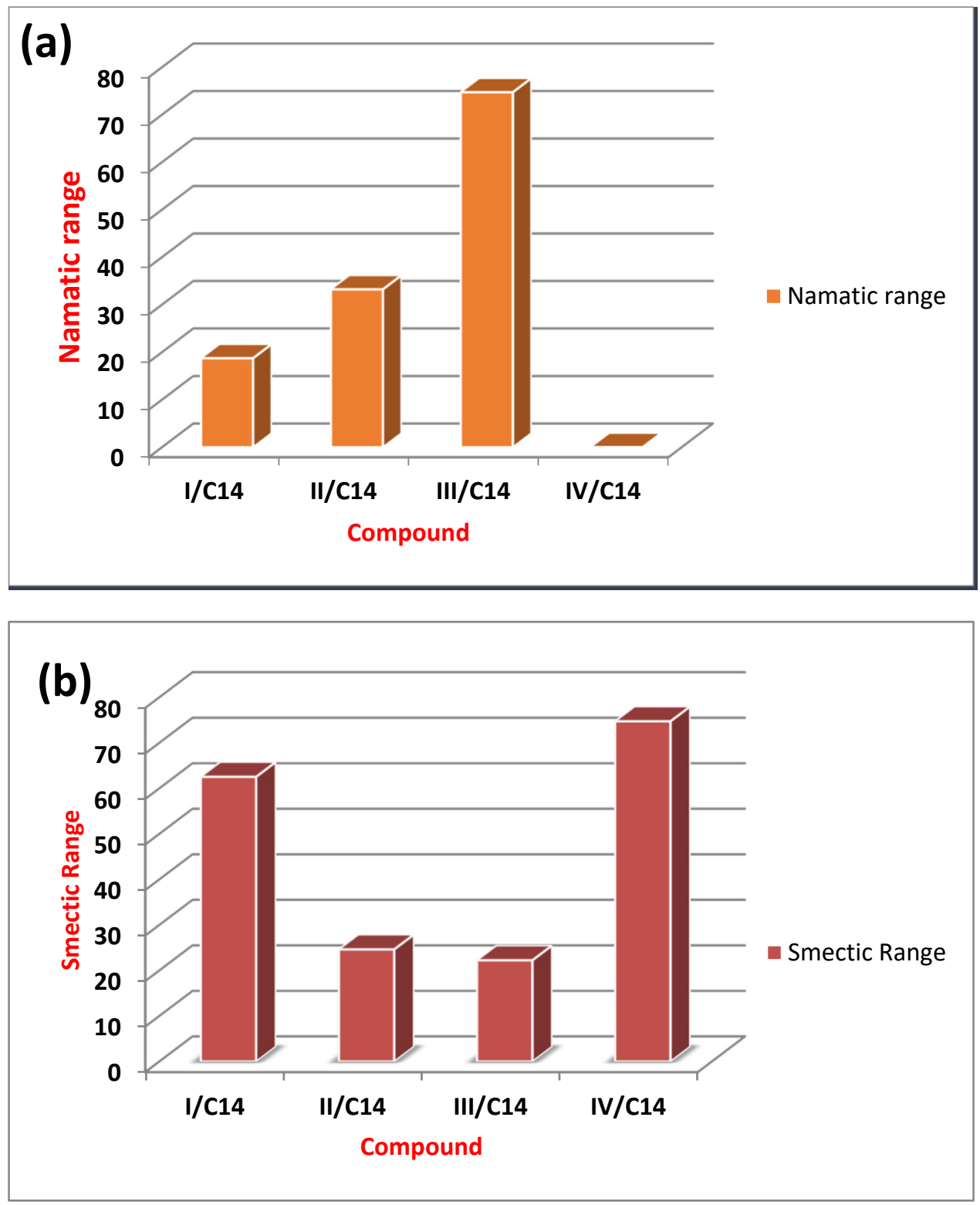

Figure 5. Cont. 


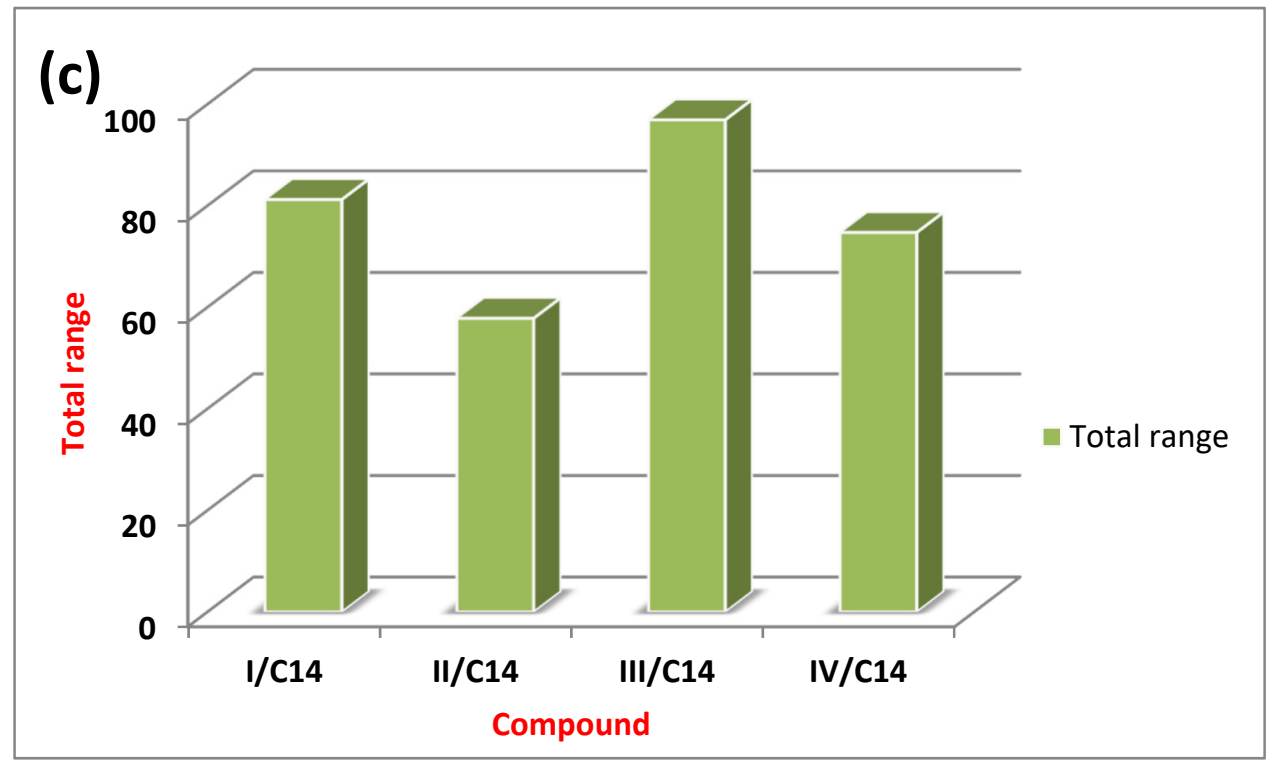

Figure 5. The relation between the type of the polar group and nematic (a), smectic (b) and total (c) mesophase range of the investigated compounds (I-IV)C14.

\section{Conclusions}

Supramolecular two-ring, Schiff base, novel low-melting ILCs were prepared and investigated thermally and optically by means of DSC and POM. The IL compounds were fabricated from 4-substituted aniline ( $\mathrm{MeO}, \mathrm{Cl}, \mathrm{Br}$ and $\mathrm{F}$ derivatives) and 4-pyridine carbaldehyde and then mixed in equimolar ratios with linear 1-bromo alkanes at different chain lengths, namely C6, C8, and C14. Only the IL analogues composed of Schiff bases with the 1-bromotetradecane exhibit mesomorphic behavior. All of these ILs, excluding the monomorphic SmA monotropic F-substituted compound, exhibit dimorphic enantiotropic mesophases, namely SmA followed by $\mathrm{N}$ mesophases according to temperature increment. The DSC and POM results for the induced mesophases were then treated by the density functional theory (DFT). The results proved that the group polarity strongly influences both the mesomorphic ranges and mesophase stabilities of the prepared ILCs. The experimental results were in direct agreement with the theoretical data obtained by DFT.

Author Contributions: Data curation, S.Z.M., D.M.A., M.M.T.E.-T., M.T.A., Y.E.K., M.A.Z., K.A.A.A.-O. and M.H.; Formal analysis, M.A.Z.; Funding acquisition, S.Z.M., D.M.A., M.M.T.E.-T. and K.A.A.A.-O.; Investigation, M.T.A. and M.H.; Methodology, S.Z.M. and M.T.A.; Resources, Y.E.K.; Writing-original draft, S.Z.M. and M.M.T.E.-T.; Writing-review \& editing, S.Z.M. All authors have read and agreed to the published version of the manuscript.

Funding: This research was funded by King Saud University, Riyadh, Saudi Arabia. Project number (RSP-2021/402).

Institutional Review Board Statement: Not applicable.

Informed Consent Statement: Not applicable.

Data Availability Statement: Not applicable.

Acknowledgments: The authors extend their appreciation to the Researchers Supporting Project number (RSP-2021/402), King Saud University, Riyadh, Saudi Arabia.

Conflicts of Interest: The authors declare no conflict of interest. 


\section{References}

1. Halperin, B.; Nelson, D. Melting and liquid crystals in two dimensions. In Light Scattering in Solids; Springer: Berlin/Heidelberg, Germany, 1979; pp. 47-57.

2. Fragiadakis, D.; Roland, C. Connection between dynamics and thermodynamics of liquids on the melting line. Phys. Rev. E 2011, 83, 031504. [CrossRef] [PubMed]

3. Goodby, J.W.; Collings, P.J.; Kato, T.; Tschierske, C.; Gleeson, H.; Raynes, P.; Vill, V. Handbook of Liquid Crystals, 8 Volume Set; John Wiley \& Sons: Hoboken, NJ, USA, 2014; Volume 1.

4. Welton, T. Room-temperature ionic liquids. Solvents for synthesis and catalysis. Chem. Rev. 1999, 99, 2071-2084. [CrossRef] [PubMed]

5. Chiappe, C.; Pieraccini, D. Kinetic study of the addition of trihalides to unsaturated compounds in ionic liquids. Evidence of a remarkable solvent effect in the reaction of ICl2. J. Org. Chem. 2004, 69, 6059-6064. [CrossRef]

6. $\quad$ Earle, M.J.; Esperança, J.M.; Gilea, M.A.; Lopes, J.N.C.; Rebelo, L.P.; Magee, J.W.; Seddon, K.R.; Widegren, J.A. The distillation and volatility of ionic liquids. Nature 2006, 439, 831-834. [CrossRef] [PubMed]

7. Rogers, R.D.; Seddon, K.R. Ionic liquids-Solvents of the future? Science 2003, 302, 792-793. [CrossRef]

8. Sheldon, R.A. Green solvents for sustainable organic synthesis: State of the art. Green Chem. 2005, 7, 267-278. [CrossRef]

9. Wasserscheid, P.; Keim, W. Ionic liquids-New "solutions" for transition metal catalysis. Angew. Chem. Int. Ed. 2000, 39, 3772-3789. [CrossRef]

10. Peppel, T.; Köckerling, M. New low-melting triply charged homoleptic Cr (III)-based ionic liquids in comparison to their singly charged heteroleptic analogues. Materials 2021, 14, 2676. [CrossRef] [PubMed]

11. de Fremont, P.; Marion, N.; Nolan, S.P. Carbenes: Synthesis, properties, and organometallic chemistry. Coord. Chem. Rev. 2009, 253, 862-892. [CrossRef]

12. Hahn, F.E.; Jahnke, M.C. Heterocyclic carbenes: Synthesis and coordination chemistry. Angew. Chem. Int. Ed. 2008, 47, 3122-3172. [CrossRef]

13. Hopkinson, M.N.; Richter, C.; Schedler, M.; Glorius, F. An overview of N-heterocyclic carbenes. Nature 2014, 510, 485-496. [CrossRef] [PubMed]

14. Salikolimi, K.; Sudhakar, A.A.; Ishida, Y. Functional ionic liquid crystals. Langmuir 2020, 36, 11702-11731. [CrossRef]

15. Causin, V.; Saielli, G. Ionic liquid crystals. In Green Solvents II; Springer: Berlin/Heidelberg, Germany, 2012 ; pp. 79-118.

16. Sakaebe, H.; Matsumoto, H. N-Methyl-N-propylpiperidinium bis (trifluoromethanesulfonyl) imide (PP13-TFSI)-novel electrolyte base for Li battery. Electrochem. Commun. 2003, 5, 594-598. [CrossRef]

17. Freire, M.G.; Santos, L.M.; Fernandes, A.M.; Coutinho, J.A.; Marrucho, I.M. An overview of the mutual solubilities of waterimidazolium-based ionic liquids systems. Fluid Phase Equilibria 2007, 261, 449-454. [CrossRef]

18. Yi, F.; Peng, Y.; Song, G. Microwave-assisted liquid-phase synthesis of methyl 6-amino-5-cyano-4-aryl-2-methyl-4H-pyran-3carboxylate using functional ionic liquid as soluble support. Tetrahedron Lett. 2005, 46, 3931-3933. [CrossRef]

19. Bates, E.D.; Mayton, R.D.; Ntai, I.; Davis, J.H. $\mathrm{CO}_{2}$ capture by a task-specific ionic liquid. J. Am. Chem. Soc. 2002, 124, 926-927. [CrossRef]

20. Cole, A.C.; Jensen, J.L.; Ntai, I.; Tran, K.L.T.; Weaver, K.J.; Forbes, D.C.; Davis, J.H. Novel Brønsted acidic ionic liquids and their use as dual solvent- catalysts. J. Am. Chem. Soc. 2002, 124, 5962-5963. [CrossRef]

21. Li, J.; Peng, Y.; Song, G. Mannich reaction catalyzed by carboxyl-functionalized ionic liquid in aqueous media. Catal. Lett. 2005, 102, 159-162. [CrossRef]

22. Davis Jr, J.H.; Forrester, K.J.; Merrigan, T. Novel organic ionic liquids (OILs) incorporating cations derived from the antifungal drug miconazole. Tetrahedron Lett. 1998, 39, 8955-8958. [CrossRef]

23. Jodry, J.J.; Mikami, K. New chiral imidazolium ionic liquids: 3D-network of hydrogen bonding. Tetrahedron Lett. 2004, 45, 4429-4431. [CrossRef]

24. Fei, Z.; Geldbach, T.J.; Zhao, D.; Dyson, P.J. From dysfunction to bis-function: On the design and applications of functionalised ionic liquids. Chem.-A Eur. J. 2006, 12, 2122-2130. [CrossRef] [PubMed]

25. Lee, S.-G. Functionalized imidazolium salts for task-specific ionic liquids and their applications. Chem. Commun. 2006, 1049-1063. [CrossRef] [PubMed]

26. Hadjikakou, S.K.; Hadjiliadis, N. Antiproliferative and anti-tumor activity of organotin compounds. Coord. Chem. Rev. 2009, 253, 235-249. [CrossRef]

27. Garoufis, A.; Hadjikakou, S.; Hadjiliadis, N. Palladium coordination compounds as anti-viral, anti-fungal, anti-microbial and anti-tumor agents. Coord. Chem. Rev. 2009, 253, 1384-1397. [CrossRef]

28. Liu, C.-M.; Xiong, R.-G.; You, X.-Z.; Liu, Y.-J.; Cheung, K.-K. Crystal structure and some properties of a novel potent Cu $\mathrm{Zn}_{2} \mathrm{SOD}$ model schiff base copper (II) complex $*[\mathrm{Cu}(\mathrm{bppn})]\left(\mathrm{ClO}_{4}\right)_{2} *_{2} \cdot \mathrm{H}_{2} \mathrm{O}$. Polyhedron 1996, 15, 4565-4571. [CrossRef]

29. Atkins, A.J.; Black, D.; Blake, A.J.; Marin-Becerra, A.; Parsons, S.; Ruiz-Ramirez, L.; Schröder, M. Schiff-base compartmental macrocyclic complexes. Chem. Commun. 1996, 457-464. [CrossRef]

30. Golcu, A.; Tumer, M.; Demirelli, H.; Wheatley, R.A. Cd (II) and Cu (II) complexes of polydentate Schiff base ligands: Synthesis, characterization, properties and biological activity. Inorg. Chim. Acta 2005, 358, 1785-1797. [CrossRef]

31. Mohindru, A.; Fisher, J.M.; Rabinovitz, M. Bathocuproine sulphonate: A tissue culture-compatible indicator of copper-mediated toxicity. Nature 1983, 303, 64-65. [CrossRef] 
32. Patel, P.; Thaker, B.; Zele, S. Preparation and characterisation of some lanthanide complexes involving a heterocyclic $\beta-$ diketone. Indian J. Chem. 1999, 38A, 563-567.

33. Mohammady, S.Z.; Aldhayan, D.M.; Hagar, M. Pyridine-based three-ring bent-shape supramolecular hydrogen bond-induced liquid crystalline complexes: Preparation and density functional theory investigation. Crystals 2021, 11, 628. [CrossRef]

34. Mohammady, S.Z.; Aldhayan, D.M.; Hagar, M. Preparation and DFT study for new three-ring supramolecular H-bonded induced liquid crystal complexes. Front. Chem. 2021, 9, 679528. [CrossRef]

35. Boyer, N.; Gloanec, P.; De Nanteuil, G.; Jubault, P.; Quirion, J.-C. Chemoselective and stereoselective synthesis of gem-difluoro- $\beta$ aminoesters or gem-difluoro- $\beta$-lactams from ethylbromodifluoroacetate and imines during Reformatsky reaction. Tetrahedron 2007, 63, 12352-12366. [CrossRef]

36. Krishna Murthy, A.; Chalapathy, A.; Srinivasulu, M.; Madhumohan, M.; Rao, Y.; Potukuchi, D. Influence of flexible chain, polar substitution and hydrogen bonding on phase stability in Shiff based (4) PyBD (4I) BrA-nOBA series of liquid crystals. Mol. Cryst. Liq. Cryst. 2018, 664, 46-68. [CrossRef]

37. Nafee, S.S.; Ahmed, H.A.; Hagar, M. New architectures of supramolecular H-bonded liquid crystal complexes based on dipyridine derivatives. Liq. Cryst. 2020, 47, 1811-1824. [CrossRef]

38. Katariya, K.D.; Nakum, K.J.; Hagar, M. New fluorinated azo/schiff base liquid crystals: Synthesis, characterisation, mesomorphic study and DFT calculations. Liq. Cryst. 2021, 1-15. [CrossRef]

39. Zakaria, M.A.; Alazmi, M.; Katariya, K.D.; El Kilany, Y.; El Ashry, E.S.H.; Jaremko, M.; Hagar, M.; Mohammady, S.Z. Mesomorphic Behaviour and DFT Insight of Arylidene Schiff Base Liquid Crystals and Their Pyridine Impact Investigation. Crystals 2021, 11, 978. [CrossRef]

40. Mohammady, S.Z.; Aldhayan, D.M.; Alshammri, M.A.; Alshammari, A.K.; Alazmi, M.; Katariya, K.D.; Jaremko, M.; Hagar, M. Polar alkoxy group and pyridyl effects on the mesomorphic behavior of new non-symmetrical schiff base liquid crystals. Symmetry 2021, 13, 1832. [CrossRef]

41. Ahmed, H.; Mansour, E.; Hagar, M. Mesomorphic study and DFT simulation of calamitic Schiff base liquid crystals with electronically different terminal groups and their binary mixtures. Liq. Cryst. 2020, 47, 2292-2304. [CrossRef] 